\title{
Black-Scholes Model of European Call Option Pricing in Constant Market Condition
}

\author{
Retno Tri Vulandari and Sutrima
}

\begin{abstract}
Investment is a saving activity with the aim of overcoming price increases or often called inflation. Investments can be in the form of gold, property, silver or stock investments. Stock investment is considered more profitable than just saving at a bank. Currency values are declining due to inflation. This results in a tendency to invest in shares. Stock investment carries a great risk. Therefore, in 2004 stock options began to trade. Stock options are contracts that give the holder the right to buy / sell shares at the agreed time, at a certain price. Stock option prices tend to be cheaper than stock prices. Therefore, determining the right price of stock options is needed. In this study, we will focus on the European type of buying options, the right to buy shares at an agreed price at maturity. The purpose of this study is the completion of the Black-Scholes model of European type option prices at a constant market, assuming stock movements meet the stochastic differential equation, fixed riskfree interest rates, companies distributing dividends, no taxes, no transaction costs, and free market arbitration. The results of this research are in the form of differential equations and the settlement of the Black-Scholes model of European type call option prices, and a case study used by stock option contracts with a maturity of January 4, 2010, PT Aqua Golden Mississippi Tbk.
\end{abstract}

Index Terms-Stock Option, Black-scholes, Constant Market.

\section{INTRODUCTION}

$\mathbf{M}$ ANY ways to invest wealth. One way to invest wealth is to sell stocks. The price of stocks traded changes from time to time. Uncertainty of changes in stock prices causes stock trading has risk. Options are an alternative to reducing risk in stock trading. Option is a right based on an agreement to buy or sell stocks at an agreed price at the end of the maturity date or before the maturity date. This is described in Atmaja [1].

Based on the type of rights granted, options consist of a buy option (call option) and a sell option (put option). Buying option is a right to buy stocks at the agreed price and within a certain agreed period of time. Selling option is a right to sell stocks at the agreed price and within a certain agreed period of time. Based on the maturity date, there are 2 types of options namely American type options and European type options. American type options are options that can be exercised at any time before or at maturity. European type options are options that can be exercised when due.

According to Atmaja [1], this European type option follows the Black-Scholes model. The Black-Scholes model is an option price valuation model that has been widely accepted

Manuscript received August 29, 2019; accepted August 5, 2020.

R.T. Vulandari is with the STMIK Sinar Nusantara, Indonesia. E-mail: vulandari.sinus@gmail. com

Sutrima is with the Universitas Sebelas Maret, Indonesia. E-mail: sutrimadstaff.uns.ac.id in the financial sector. This model was developed by Fisher Black and Myron Scholes in 1973. Assuming this model is that stocks do not provide dividend payments, there are no transaction costs, risk-free interest rates.

Many studies have examined the price of the Black-Scholes model option. For example research that has been done by Kurniasari [2]. However, research conducted generally still assumes no distribution of dividends on stocks. The fact that occurs in the market is not all the option price agreements without dividends.

According to Kanniainen [3], dividends are the distribution of a company's profits to stockholders. Dividend distribution will reduce the price of the option. Dividends are distributed in two conditions, namely constant market and continuous market. The state of a constant market is the condition of a stock option contract that assumes a risk-free interest rate constant $r$ and the distribution of a constant dividend $q$. Therefore, this paper discusses the Black-Scholes model of European type option purchase prices by dividend distribution and is applied to the stock option contracts of PT. Aqua Golden Mississippi Tbk.

\section{RESEARCH MEthods}

Discussion of the problem has been formulated using references in the form of books on economics, journals and writings that are published on the website. The following 9 operational steps are used to achieve the research objectives:

1) Determine two types of conditions at the time of dividend distribution, namely the state of the constant market and the state of the continuous market.

2) Determine the expected value of stocks at maturity, the stock will decrease as the present value of the dividends distributed,

3) Reducing the Black-Scholes model of the European type of option purchase price by dividend distribution through the portfolio equation.

4) Completing the Black-Scholes model of European type option purchase prices by dividend distribution, i.e. for constant markets, the model is completed with a neutral risk assessment which means the expected value of stock returns equals risk-free interest rates,

5) Test the assumption of normality of weekly stock prices with natural logarithmic transformation (ln).

6) Estimating stock price volatility with annual standard deviations from ln stock returns.

7) Determine the risk-free interest rate, which is the constant market situation, the Bank Indonesia interest rate is used in January 2010. 
8) Determine dividends, i.e. conditions of constant market use, November 12, 2010 dividends.

9) Determine the price of a European Call Option based on a stock option contract.

\section{EXPERIMENTS AND RESULTS}

\section{A. Determination of Stock Expectation Value at Maturity in a Constant Market}

Investors hope that option investment is more profitable than stock investment (leverage). In investing, options are assumed that all option investors are risk neutral. If the company does not distribute dividends, then the current stock price is

$$
S=E\left(S_{T}\right) \exp [-r(T-t)]
$$

for all $T>t$. According to Kanniainen [3], if a company distributes dividends, the expected value of shares at maturity is

$$
S=E\left(S_{T}+q\right) \exp [-r(T-t)] .
$$

So that when ex-dividend shares will experience a price decrease equal to the present value of the dividends distributed, i.e.

$$
E\left(S_{T}\right)=S-q \exp [-r(T-t)]
$$

\section{B. Determination of Portfolio Equations in a Constant Market}

A portfolio is a collection of securities owned by a person or party managed by a mutual fund. The purpose of the portfolio is to minimize risk to options. The assumption used to determine the price of a European type of purchase option by dividend distribution in a constant market state is

1) the assets underlying the price movement meet the stochastic differential equation

$$
\frac{d S_{t}}{S_{t}}=\mu d t+\sigma d W_{t}
$$

2) the risk-free interest rate is constant $r$,

3) the company distributes $q$ dividends, which results in a reduced stock price of $q S$,

4) there are no transaction fees, no taxes, and a free market arbitration.

By applying the Itô formula to equation (3) for $\bar{C}(S, t)$, we obtained

$$
d \bar{C}=\frac{\partial \bar{C}}{\partial t} d t+\frac{\partial \bar{C}}{\partial S_{t}} d S_{t}+\frac{1}{2} \sigma^{2} S_{t}^{2} \frac{\partial^{2} \bar{C}}{\partial S_{t}^{2}} d t
$$

The formation of the portfolio $\Pi t$ is influenced by the price of option $C^{-}$and the value of $\Delta$ hedging. Therefore, the portfolio value at time $t$ is formulated as

$$
\Pi_{t}=\bar{C}-\Delta S_{t} .
$$

The hedging value is intended to reduce losses if there is a stock price movement that is not as expected. This can happen with the choice of ed hedging which results in the value of the portfolio $\Pi$ risk free in time $(t, t+d t)$. Portfolio value is risk free when $t+d t$ is formulated as

$$
\frac{\Pi_{t+d t}-\Pi_{t}}{\Pi_{t}}=r d t
$$

If there is dividend distribution, the portfolio value $\Pi$ when $t+d t$ is

$$
\Pi_{t+d t}=\bar{C}_{t+d t}-\Delta_{t} S_{t} q-\Delta_{t} S_{t+d t}
$$

With the substitution of equations (5) and (6), we obtained

$$
d \bar{C}-\Delta_{t} d S_{t}=r \Pi_{t} d t+\Delta_{t} S_{t} q d t
$$

From equations (4) and (7), we obtained

$$
\frac{d \bar{C}}{d t}+\frac{1}{2} \sigma^{2} S_{t}^{2} \frac{\partial^{2} \bar{C}}{\partial S_{t}^{2}}+(r-q) S_{t} \frac{\partial \bar{C}}{\partial S_{t}}-r \bar{C}=0
$$

where $C^{-}(S, t)$ denotes the European type option purchase price by dividing the dividend against $S$ and $t$. Equation (8) is known as the Black-Scholes model of European type option purchase prices by dividend distribution in a constant market situation.

\section{Black-Scholes Model of European Call Option Pricing With Dividend in a Constant Market}

According to Hidayati [4], the Black-Scholes model can be derived using a neutral risk assessment. The expected value of neutral risk is

$$
E\left[\max \left\{S_{t}-K, 0\right\}\right] .
$$

The value of $C(S, t)$ is the expected value at neutral risk multiplied by the discount value

$$
C(S, t)=e^{-r(T-t)} E\left[\max \left\{S_{t}-K, 0\right\}\right]
$$

Lemma 1: Let $g\left(S_{t}\right)$, be the probability density function of $S_{t}$, then

$e^{-r(T-t)} \int_{K}^{\infty} S_{t} g\left(S_{t}\right) d S_{t}=S N\left(\frac{\ln S+\left(r+\frac{1}{2} \sigma^{2}\right)(T-t)-\ln K}{\sigma \sqrt{T-t}}\right)$.

Proof: Let $g\left(S_{t}\right)$, be the probability density function of $S_{t}$, then

$e^{-r(T-t)} \int_{K}^{\infty} S_{t} g\left(S_{t}\right) d S_{t}=e^{-r(T-t)} \int_{K}^{\infty} S_{t} \frac{1}{S_{t} \sigma \sqrt{2 \pi}} e^{-\frac{1}{2}\left(\frac{\ln S_{t}-\mu}{\sigma}\right)^{2}} d S_{t}$

For example when $z=\ln S_{t}$, we obtained

$$
\begin{array}{r}
e^{-r(T-t)} \int_{K}^{\infty} S_{t} \frac{1}{S_{t} \sigma \sqrt{2 \pi}} e^{-\frac{1}{2}\left(\frac{\ln S_{t}-\mu}{\sigma}\right)^{2}} d S_{t}= \\
S \int_{\ln K}^{\infty} \frac{1}{\sigma \sqrt{2 \pi}} e^{\frac{-\left[z-\left(\sigma^{2}+\mu\right)\right]^{2}}{2 \sigma^{2}}}
\end{array}
$$

For example $p=\frac{z-\left(\sigma^{2}+\mu\right)}{\sigma}$, from this equation, it can be written as $z=\sigma p+\left(\sigma^{2}+\mu\right)$. Therefore $\frac{d z}{d p}=\sigma$, as a result $S \int_{\ln K}^{\infty} \frac{1}{\sigma \sqrt{2 \pi}} e^{\frac{-\left[z-\left(\sigma^{2}+\mu\right)\right]^{2}}{2 \sigma^{2}}} d z=S N\left(\frac{\left(\sigma^{2}+\mu\right)-\ln K}{\sigma}\right)$

Lemma 2: Let $g\left(S_{t}\right)$, be the probability density function of $S_{t}$, then

$$
\begin{array}{r}
e^{-r(T-t)} \int_{K}^{\infty} K g\left(S_{t}\right) d S_{t}= \\
K e^{-r(T-t)} N\left(\frac{\ln S+\left(r-\frac{1}{2} \sigma^{2}\right)(T-t)-\ln K}{\sigma \sqrt{T-t}}\right) .
\end{array}
$$


Proof: Let $g\left(S_{t}\right)$ be the probability density function of $S_{t}$, then

$e^{-r(T-t)} \int_{K}^{\infty} K g\left(S_{t}\right) d S_{t}=e^{-r(T-t)} K \int_{K}^{\infty} \frac{1}{S_{t} \sigma \sqrt{2 \pi}} e^{-\frac{1}{2}\left(\frac{\ln S_{t}-\mu}{\sigma}\right)^{2}} d S_{t}$.

For example $z=\ln S_{t}$, we obtained

$$
\begin{array}{r}
e^{-r(T-t)} K \int_{K}^{\infty} \frac{1}{S_{t} \sigma \sqrt{2 \pi}} e^{-\frac{1}{2}\left(\frac{\ln S_{t}-\mu}{\sigma}\right)^{2}} d S_{t}=e^{-r(T-t)} K \\
\int_{\ln K}^{\infty} \frac{1}{\sigma \sqrt{2 \pi}} e^{-\frac{1}{2}\left(\frac{z-\mu}{\sigma}\right)^{2}} d z
\end{array}
$$

For example $v=(z-\mu) / \sigma$. This equation can be written as $z=\sigma v+\mu$. Therefore $d z / d v=\sigma$, as a result

$$
e^{-r(T-t)} K \int_{\ln K}^{\infty} \frac{1}{\sigma \sqrt{2 \pi}} e^{-\frac{1}{2}\left(\frac{z-\mu}{\sigma}\right)^{2}} d z=e^{-r(T-t)} K N\left(\frac{\mu-\ln K}{\sigma}\right)
$$

Lemma 3: Let $g\left(S_{t}\right)$ be a function of the probability density of $S_{t}$, and $q$ is a constant dividend, then

$$
\begin{array}{r}
e^{-r(T-t)} \int_{K}^{\infty}\left(-q S_{t}\right) g\left(S_{t}\right) d S_{t}= \\
-q N\left(\frac{\ln S+\left(r+\frac{1}{2} \sigma^{2}\right)(T-t)-\ln K}{\sigma \sqrt{T-t}}\right) .
\end{array}
$$

Proof: Let $g\left(S_{t}\right)$ be a function of the probability density of $S_{t}$ and $q$ is a constant dividend, then

$$
\begin{array}{r}
e^{-r(T-t)} \int_{K}^{\infty}-q S_{t} g\left(S_{t}\right) d S_{t}= \\
e^{-r(T-t)} \int_{K}^{\infty}-q S_{t} \frac{1}{S_{t} \sigma \sqrt{2 \pi}} e^{-\frac{1}{2}\left(\frac{\ln S_{t}-\mu}{\sigma}\right)^{2}} d S_{t} .
\end{array}
$$

For example, when $z=\ln S_{t}$ we obtained

$$
\begin{array}{r}
e^{-r(T-t)} \int_{K}^{\infty}-q \frac{1}{S_{t} \sigma \sqrt{2 \pi}} e^{z-\frac{1}{2}\left(\frac{z-\mu}{\sigma}\right)^{2}} d z= \\
-q \int_{\ln K}^{\infty} \frac{1}{S_{t} \sigma \sqrt{2 \pi}} e^{\frac{-\left[z-\left(\sigma^{2}+\mu\right)\right]^{2}}{2 \sigma^{2}}} d z .
\end{array}
$$

For example $p=\left(z-\left(\sigma^{2}+\mu\right)\right) / \sigma$. This equation can be written as $z=p \sigma+\left(\sigma^{2}+\mu\right)$. Therefore $d z / d p=\sigma$, as a result

$$
-q \int_{\ln K}^{\infty} \frac{1}{\sigma \sqrt{2 \pi}} e^{\frac{-\left[z-\left(\sigma^{2}+\mu\right)\right]^{2}}{2 \sigma^{2}}} d z=-q N\left(\frac{\left(\sigma^{2}+\mu\right)-\ln K}{\sigma}\right)
$$

where $\frac{\left(\sigma^{2}+\mu\right)-\ln K}{\sigma}=\frac{\ln S+\left(r+\frac{1}{2} \sigma^{2}\right)(T-t)-\ln K}{\sigma \sqrt{T-t}}$.

Theorem 1: The European option purchase price by dividend distribution in a constant market state is

$$
\bar{C}(S, t)=\left(S-q e^{-r(T-t)}\right) N\left(d_{1}\right)-K e^{-r(T-t)} N\left(d_{2}\right)
$$

Proof: Based on equation (9), we obtained the price of a European type purchase option by dividend distribution in a constant market state

$$
\begin{gathered}
\bar{C}(S, t)=e^{-r(T-t)} E\left[\max \left\{S_{t}-K, C(-q S, t)\right\}\right] \\
\bar{C}(S, t)=e^{-r(T-t)}\left[\int_{K}^{\infty}\left(S_{t}-K\right) g\left(S_{t}\right) d S_{t}+\right. \\
\left.\left(e^{-r(T-t)} \int_{K}^{\infty}-q S_{t} g\left(S_{t}\right) d S_{t}\right)\right]
\end{gathered}
$$

Based on Lemma 1, Lemma 2, and Lemma 3, we have shown the following

$$
\bar{C}(S, t)=\left(S-q e^{-r(T-t)}\right) N\left(d_{1}\right)-K e^{-r(T-t)} N\left(d_{2}\right)
$$

where

$$
\begin{aligned}
& d_{1}=\frac{\ln S+\left(r+\frac{1}{2} \sigma^{2}\right)(T-t)-\ln K}{\sigma \sqrt{T-t}}, \\
& d_{2}=\frac{\ln S+\left(r-\frac{1}{2} \sigma^{2}\right)(T-t)-\ln K}{\sigma \sqrt{T-t}}
\end{aligned}
$$

Thus, the settlement of the Black-Scholes model of European type purchase option prices by dividend distribution in a constant market state is equation (10).

\section{Estimates of $\mu$ and $\sigma^{2}$}

Volatility is estimated by the standard deviation of stock returns per unit time. The Black-Scholes model requires estimation of volatility over the life of the options in the future. Volatility during the life of stock options is estimated by a measurement of past stock volatility called historical volatility.

Here are listed 6 main steps to estimate the volatility of stock prices referred to from Hidayati [4]:

1) Determining the number of weeks in stock trading is $n+1$ for example $S_{t}$ closing price $t=1.2, \ldots, 145$.

2) Calculates $\ln$ weekly stock returns, StockReturn $=\frac{S_{t+1}}{S_{t}}$, $t=1.2, \ldots, 145$

3) Calculates the estimated mean $\ln$ stock return,

$$
\hat{\mu}=\bar{R}_{t}=\frac{\sum_{t=1}^{144} R_{t}}{144}=\frac{-0.3066167}{144}=-0.0021129
$$

stock return value 0.9978 means $99.78 \%$ expected rate of return from stock investment PT. Aqua Golden Mississippi Tbk.

4) Calculates the estimated variance of ln stock returns,

$$
s^{2}=\frac{\sum_{t=1}^{n}\left(R_{t}-\bar{R}_{t}\right)^{2}}{n-1}=0.001988
$$

5) Calculates the estimated variance of $\ln$ annual stock returns because of weekly data with the number of trading weeks in 3 years $=n+1$ week, $=1$ week $=3$ / (number of trading weeks) years $=3 / 145$ years, variance of annual stock returns ln,

$$
s_{t}^{2}=\frac{1}{\Delta t} \frac{\sum_{t=1}^{n}\left(R_{t}-\bar{R}_{t}\right)^{2}}{n-1}=0.09609
$$

6) Calculates the estimated stock price volatility with the standard deviation of annual stock returns,

$$
s_{t}=\sqrt{\frac{1}{\Delta t} \frac{\sum_{t=1}^{n}\left(R_{t}-\bar{R}_{t}\right)^{2}}{n-1}}=0.3099
$$

volatility value of 0.3099 means that $30.99 \%$ of the deviation that might occur against the expected return. 


\section{E. Risk Free Interest Rates}

In a neutral risk situation, the expected value of stock returns $(\mu)$ is equal to the risk-free interest rate $(r)$. The interest rate used is the interest rate applicable to the country concerned, such as in Indonesia using the standardization of Bank Indonesia interest rates. Bank Indonesia interest rate data used by Bank Indonesia interest rate data from August 2006 to January 2010. The data was obtained from http://www.bi.go.id/. The constant market conditions used by Bank Indonesia in January 2010 are 0.065 .

\section{F. Dividend}

Dividend data used are dividends distributed by PT. Aqua Golden Mississippi Tbk. from 7 February 1990 to 12 November 2009. The data was obtained from http://finance.yahoo.com/. On November 12, 2009, PT Aqua Golden Mississippi distributed a dividend of 0.145 per stock. Based on PT. Aqua Golden Mississippi Tbk. seen maturity of 3 months and time of ex-dividend $(t) 1$ month.

\section{G. European Call Option Pricing}

Black-Scholes model of European Call Option Pricing With Dividend in a Constant Market on January 4, 2010 is current share price $(S)$ : 16.61 , deal price $(K): 17.50$, maturity $(T): 3$ months, ex-dividend time $(t)$ : 1 month, risk free interest rate $(r): 0.065$, constant dividend $(q): 0.145$, volatility value $(\sigma)$ : 0.3099 , then

$$
\begin{aligned}
& d_{1}=\frac{\ln S+\left(r+\frac{1}{2} \sigma^{2}\right)(T-t)-\ln K}{\sigma \sqrt{T-t}}=-0.2636 \\
& d_{2}=\frac{\ln S+\left(r-\frac{1}{2} \sigma^{2}\right)(T-t)-\ln K}{\sigma \sqrt{T-t}}=-0.3901
\end{aligned}
$$

Thus, Black-Scholes model of European call option pricing with dividend in a constant market on January 4, 2010 is

$$
\bar{C}(S, t)=\left(S-q e^{-r(T-t)}\right) N\left(d_{1}\right)-K e^{-r(T-t)} N\left(d_{2}\right)=0.4924 .
$$

It means that the buyer of the European Call Options obliged to pay an option price of 0.4924 per share and has the right to buy PT. Aqua Golden Mississippi Tbk with an exercise price of 17.50 per share.

\section{CONCLUSIONS}

Black-Scholes model of European call option pricing with dividend in a constant market is

$$
\frac{d \bar{C}}{d t}+\frac{1}{2} \sigma^{2} S^{2} \frac{\partial^{2} \bar{C}}{\partial S^{2}}+(r-q) S \frac{\partial \bar{C}}{\partial S}-r \bar{C}=0
$$

Settlement of Black-Scholes model of European call option pricing with dividend in a constant market is

$$
\bar{C}(S, t)=\left(S-q e^{-r(T-t)}\right) N\left(d_{1}\right)-K e^{-r(T-t)} N\left(d_{2}\right)
$$

In the stock option contract of PT. Aqua Golden Mississippi Tbk., The purchase option price with a maturity date of January 4, 2010 in a constant market condition is 0.4924 per share.

\section{REFERENCES}

[1] L. Atmaja, Manajemen keuangan. Andi Offset, 2003.

[2] D. Kurniasari, "Penentuan nilai opsi beli tipe eropa in the money untuk model black-scholes," Ph.D. dissertation, Universitas Gadjah Mada, 2004.

[3] J. Kanniainen, "On dividend expectations and stock return volatility," International Research Journal of Finance and Economics, vol. 12, no. 3, pp. 116-132, 2007.

[4] H. Hidayati, "Penentuan nilai opsi beli tipe amerika dengan pembayaran dividen proposional," Ph.D. dissertation, Universitas Gadjah Mada, 2006. 